\title{
Targeted delivery of cisplatin to tumor xenografts via the nanoparticle component of nano-diamino-tetrac
}

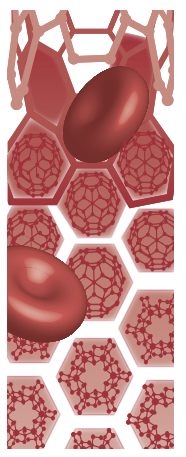

\begin{abstract}
Aim: Nano-diamino-tetrac (NDAT) targets a receptor on integrin $\alpha v \beta 3 ; \alpha v \beta 3$ is generously expressed by cancer cells and dividing endothelial cells and to a small extent by nonmalignant cells. The tetrac (tetraiodothyroacetic acid) of NDAT is covalently bound to a poly(lactic-co-glycolic acid) nanoparticle that encapsulates anticancer drugs. We report NDAT delivery efficiency of cisplatin to agent-susceptible urinary bladder cancer xenografts. Materials \& methods: Cisplatin-loaded NDAT (NDATcisplatin) was administered to xenograft-bearing nude mice. Tumor size response and drug content were measured. Results: Intratumoral drug concentration was up to fivefold higher $(p<0.001)$ in NDAT-cisplatin-exposed lesions than with conventional systemic administration. Tumor volume reduction achieved was NDAT-cisplatin > NDAT without cisplatin > cisplatin alone. Conclusion: NDAT markedly enhances cisplatin delivery to urinary bladder cancer xenografts and increases drug efficacy.
\end{abstract}

First draft submitted: 26 August 2016; Accepted for publication: 24 November 2016; Published online: 19 January 2017

Keywords: cisplatin $\bullet$ integrin $\bullet$ nanotetrac $\bullet$ NDAT $\bullet$ tetraiodothyroacetic acid $\bullet$ urinary bladder carcinoma

Tumor development and growth depend on cancer cell gene transcription (DNA), upon transferring the gene transcription information via RNA to protein-making factories in cells and on the resulting synthesis of proteins that support aggressive behavior of cancers. Generic cancer chemotherapeutic agents used widely today have one or more of the following actions. One of the actions is to disable cell DNA (an example drug is cisplatin [1], which causes DNA cross-linking and distortion) or to inhibit synthesis of nucleic acid components that make up DNA and RNA (5-fluorouracil [2], methotrexate [3]). Other actions include disruption of gene transcription of specific RNAs (doxorubicin [4]), or inhibition of protein synthesis (paclitaxel [5]). Ideally, such drug effects would be limited to cancer cells, but these anticancer agents act widely on normal (nonmalignant) cells as well, causing serious side effects. The undesirable toxicity of these drugs on normal cells limits the concentrations of the drugs to which cancer cells can be exposed clinically.

Targeted delivery of drugs directly to cancer cells, sparing normal cells, is of current interest in oncologic pharmacology [6-13]. A novel nanoparticulate formulation in which tetraiodothyroacetic acid (tetrac), a ligand of and targeted to a specific receptor on the extracellular domain of plasma membrane integrin $\alpha v \beta 3$ [14], has been developed. Tetrac is chemically bonded via a short diaminopropane linker to a $150-200 \mathrm{~nm}$ poly(lacticco-glycolic acid) (PLGA) nanoparticle. The nanoparticle is capable of bearing a chemotherapeutic drug payload [15] and the integrin av $\beta 3$ is primarily expressed by cancer cells and dividing endothelial cells $[16,17]$. Thus, the tetrac-based nano-carrier offers specificity in terms of targeted anticancer drug delivery
Thangirala Sudha', Dhruba J Bharali', Murat Yalcin',2, Noureldien HE Darwish',3, Melis Debreli Coskun ${ }^{1,4}$, Kelly A Keating ${ }^{1}$, Hung-Yun Lin ${ }^{5,6}$, Paul J Davis ${ }^{*, 1,7}$ \& Shaker A Mousa'

${ }^{1}$ Pharmaceutical Research Institute, Albany College of Pharmacy \& Health Sciences, Rensselaer, NY 12144, USA ${ }^{2}$ Department of Physiology, Faculty of Veterinary Medicine, Uludag University, Gorukle, 16059 Bursa, Turkey ${ }^{3}$ Clinical Pathology Department, Hematology Unit, Faculty of Medicine, Mansoura University, Dakahliya 35516, Egypt

${ }^{4}$ Department of Biology, Faculty of Arts \& Sciences, Uludag University, Gorukle, 16059 Bursa, Turkey ${ }^{5}$ PhD Program for Cancer Biology and Drug Discovery, College of Medical Science \& Technology, Taipei Medical University, Taipei 11031, Taiwan

${ }^{6}$ Taipei Cancer Center, Taipei Medical University, Taipei 11031, Taiwan

${ }^{7}$ Department of Medicine, Albany Medical College, Albany, NY, 12208, USA *Author for correspondence:

Tel.: +1 5186947568

Fax: +1 5186947567

pdavis.ordwayst@gmail.com 


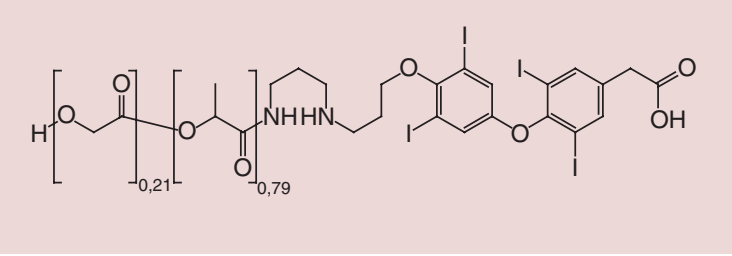

Figure 1. Chemical structure of nano-diamino-tetrac (NDAT). The chemical name is $\{4-[4-$-(3-(3-(poly-2-(2hydroxyacetotoxy)) propanamido)aminopropoxy)-3,5diiodophenoxy]-3,5-diiodophenyl\} acetic acid. The subscripted numbers 0,21 and 0,79 mean the lactic acid:glycolic acid ratio in the poly(lactic-co-glycolic acid) polymer averages 79:21.

and the prospect of reduced systemic toxicity. We have examined the efficacy of delivery by Nano-diaminotetrac (NDAT) of cisplatin to nude mouse urinary bladder cancer xenografts. We would emphasize that the delivery system includes no unbound PLGA. The delivery system is also suitable for paclitaxel and for doxorubicin, as shown in a separate report [18]. The agent NDAT (also called Nanotetrac), has the chemical name of \{4-[4-(3-(3-(poly-2-(2-hydroxyacetotoxy)) propanamido)aminopropoxy)-3,5-diiodophenoxy]3,5-diiodophenyl\} acetic acid (Figure 1).

\section{Materials \& methods}

\section{Materials}

We purchased the following supplies from SigmaAldrich (MO, USA): cisplatin (cis-diamineplatinum(II) dichloride), Dubelcco's Modified Eagle Medium (DMEM), ethyl acetate, EDTA, fetal bovine serum (FBS), hygromycin B (H3274), Matrigel ${ }^{\circledR}$, orthophenylenediamine, penicillin, phosphate-buffered saline (PBS), polyvinyl alcohol (PVA, Mowiol 4-88), N4-[2-(4-phenoxyphenyl)ethyl]-4,6-quinazolinediamine (QNZ) (EVP4593), streptomycin and all plasticware used.

\section{Synthesis of void PLGA nanoparticles, NDAT nanoparticles \& NDAT with encapsulated cisplatin}

Void PLGA nanoparticles and NDAT nanoparticles were synthesized by modification of the method in [19]. In the first step of synthesis of void nanoparticles, $5 \mathrm{ml}$ of $1 \% \mathrm{w} / \mathrm{v}$ PVA was added to $100 \mathrm{mg}$ of PLGA (avg. MW 8000, lactic acid:glycolic acid 79:21, from Evonik Industries, AL, USA) in $1 \mathrm{ml}$ of ethyl acetate, and the resultant mixture was sonicated intermittently for $90 \mathrm{~s}$ in a QSonica sonicator (model CL-188, CT, USA). Similarly, for NDAT nanoparticles, $100 \mathrm{mg}$ PLGA was conjugated to tetrac (DPx Fine Chemicals, Regensburg, Germany) instead of PLGA polymers.
The optimized method of incorporation of cisplatin to PLGA in NDAT involved $100 \mathrm{mg}$ PLGA conjugated to tetrac to which $500 \mu \mathrm{l}$ of cisplatin was added that was dissolved as $10 \mathrm{mg} / \mathrm{ml}$ in ethyl acetate. Five milliliters of $1 \%$ PVA was then added and the resultant mixture was sonicated intermittently for $90 \mathrm{~s}$. The second step of the synthesis of the nanoparticles was similar for all of the nanoparticles (void, NDAT, NDAT-cisplatin). In this step, $10 \mathrm{ml}$ of $0.05 \%$ PVA was added to each of the above mentioned mixtures and they were sonicated for $1 \mathrm{~min}$. The ethyl acetate was then removed at $45^{\circ} \mathrm{C}$ for $20 \mathrm{~min}$ under vacuum in a rotary evaporator. The entire solution was dialyzed using dialysis membrane of $12-14 \mathrm{KDa}$ cutoff for about $12 \mathrm{~h}$ by changing the bulk water at least three-times to remove the free cisplatin. Resulting nanoparticles were characterized in terms of size and surface charge using dynamic light scattering (DLS) and transmission electron microscopy (TEM).

\section{Dynamic light scattering}

The size distribution and surface charge of the synthesized nanoparticles in aqueous dispersions were determined using a Malvern zeta sizer (Malvern Instrumentation Co, MA, USA). One milliliter of the nanoparticle solution was pipetted into a $3 \mathrm{ml}$, four-sided, clear plastic cuvette and measured directly.

\section{Transmission electron microscopy}

The size and morphology of nanoparticles (void, NDAT, and NDAT-cisplatin) were examined with TEM using a JEOL JEM-100CX transmission electron microscope (JEOL, Inc., MA, USA). One drop of the corresponding nanoformulation solution was mounted on a thin film of amorphous carbon deposited on a copper grid (300 mesh). The solution was air-dried and the sample was examined directly.

\section{Determination of the amount of cisplatin} encapsulated in the nanoparticles

First, the nanoparticles were disintegrated. Then cisplatin was complexed with ortho-phenylenediamine, and the absorbance at $706 \mathrm{~nm}$ was measured with UV-Vis spectroscopy on a Nanodrop 2000C spectrophotometer (Thermo Fisher Scientific, MA, USA) as described in the literature [20,21]. The entrapment efficiency was determined using the following formula:

Entraptment efficiency (loading) $=$

$\left(\left[\right.\right.$ cisplatin $\left._{\mathrm{f}}\right) /\left(\left[\right.\right.$ cisplatin $\left._{\mathrm{t}}\right) \times 100$

where [cisplatin $_{\mathrm{f}}$ is the concentration of cisplatin in the nanoparticles and [cisplatin] $]_{t}$ is the theoretical concentration of cisplatin (= total amount of cisplatin added initially). 


\section{Cell culture}

Human urinary bladder cancer 253JBV cells (ATCC, VA, USA) were grown in DMEM supplemented with $10 \% \mathrm{FBS}, 1 \%$ penicillin and $1 \%$ streptomycin. Cells were cultured at $37^{\circ} \mathrm{C}$ to subconfluence and treated with $0.25 \%(\mathrm{w} / \mathrm{v})$ trypsin/EDTA to induce cell release from culture flasks. Cells for grafting were washed with culture medium, suspended in DMEM that was free of phenol red and FBS and subjected to counting.

\section{Animals \& xenografts}

Immunodeficient female $\mathrm{NCr}$ nude homozygous mice aged 5-6 weeks and weighing 18-20 g were purchased from Harlan Laboratories (NJ, USA). All animal studies were conducted at the animal facility of the Veteran Affairs Medical Center, NY, USA in accordance with and approved by current institutional guidelines for humane animal treatment. Mice were maintained under specific pathogen free conditions and housed under controlled conditions of temperature $\left(20-24^{\circ} \mathrm{C}\right)$ and humidity (60-70\%) and $12 \mathrm{~h}$ light/dark cycle with ad libitum access to water and food. Mice were allowed to acclimatize for 5 days before the study.

\section{Urinary bladder cancer xenografts}

For the subcutaneous bladder cancer tumor model, 253JBV cells were harvested, suspended in $100 \mu \mathrm{l}$ of DMEM with $50 \%$ Matrigel $^{\circledR}$ and $1 \times 10^{6}$ cells were implanted subcutaneously dorsally in each flank, to achieve two independent tumors per animal. Immediately prior to initiation of treatments, animals were randomized into treatment groups (five animals/ group) by tumor volume measured with Vernier calipers. Treatments were begun after detection of a palpable tumor mass (4-5 days postimplantation). The six treatments were control (PBS), cisplatin (1 mg/ $\mathrm{kg}$ bw), void PLGA nanoparticles, PLGA-cisplatin (1 $\mathrm{mg} / \mathrm{kg} \mathrm{bw})$, NDAT $(0.3 \mathrm{mg} / \mathrm{kg}$ bw tetrac equivalent) and NDAT-cisplatin $(0.3 \mathrm{mg} / \mathrm{kg}$ bw tetrac equivalent NDAT with a payload of $1 \mathrm{mg} / \mathrm{kg}$ bw cisplatin). The agents were administered daily, subcutaneously on the ventral side of the animal, for 14 days, and tumor volume was measured twice a week with calipers. The animals were terminated after 14 days because the NDATcisplatin treated tumors had reached about $50 \%$ of the size of control tumor, an optimum point at which to quantitate the cisplatin payload; longer treatment time might result in treated tumors being too small to facilitate measurement.

\section{Measurement of tumor content of cisplatin with LC-MS/MS}

Full details of sample preparation and LC-MS/MS operating parameters can be found in the supple- mentary material. In brief, a stock solution of cisplatin and an internal standard solution, together with tissue samples from the treated mice were prepared. The internal standard for cisplatin was transdiamminedichloropalladium(II). LC-MS/MS analysis was performed on an API 4000 triple quad mass spectrometer (Applied Biosystem MDS Sciex, Toronto, Canada) using Analyst 1.62 control software and configured with a Shimadzu LC-20AD pumping system, a SIL-20AC auto sampler and CTO-20AC column oven. The instrument was operated in a positive ion mode with a turbo V electrospray source. All calibration curves were plotted using linear regression with a weight factor of $1 / x$.

\section{Luciferase assay}

HeLa-NF- $\kappa$ B luciferase cells were purchased from Signosis Inc. (CA, USA) and grown in DMEM supplemented with $10 \%$ FBS, $1 \%$ penicillin, 1\% streptomycin and $50 \mu \mathrm{g} / \mathrm{ml}$ hygromycin B and maintained at $37^{\circ} \mathrm{C}$ in a $5 \% \mathrm{CO}_{2}$ humidified incubator. Cells were seeded at $1 \times 10^{5}$ cells in $2 \mathrm{ml} /$ well in six-well plates at $37^{\circ} \mathrm{C}$ for $24 \mathrm{~h}$. Test compounds were diamino-tetrac (DAT), NDAT and QNZ (an NF- $\mathrm{B}$ inhibitor), and doses used were based on pilot studies to determine optimal responses. Test compounds were added at the appropriate concentrations to the plate with fresh medium including $0.5 \%$ FBS and incubated at $37^{\circ} \mathrm{C}$ in $5 \% \mathrm{CO}_{2}$ for an additional $3 \mathrm{~h}$. For induction of transcription and to test the biological response of the promoters, the cell line was stimulated with cisplatin, and the cells were incubated at $37^{\circ} \mathrm{C}$ in $5 \% \mathrm{CO}_{2}$ for $24 \mathrm{~h}$. The luciferase activity was determined with a Luciferase Assay System (Promega, WI, USA). Briefly, cells were harvested by scraping in $200 \mu \mathrm{l}$ of $1 \times$ lysis buffer into a microcentrifuge tube, vortexing for $15 \mathrm{~s}$, and then centrifuging at $20,000 \times g$ for $5 \mathrm{~min}$. The supernatant cell lysates were collected. The luciferase activity was measured with $5 \mu$ of cell lysate and 50 $\mu \mathrm{l}$ of luciferase reagent, using a Glomax 20/20 Luminometer (Promega). Luciferase expression of each test compound was quantified as the relative light units, normalized to readings of control wells and expressed as relative $\mathrm{NF}-\kappa \mathrm{B}$ reporter activity. The mean $\%$ inhibitory effects of DAT, NDAT and QNZ at $1 \mu \mathrm{M}$ in the presence of $10 \mu \mathrm{M}$ cisplatin were calculated.

\section{Statistical analysis}

Statistical analysis was performed using one-way analysis of variance and comparing the mean \pm standard error of the mean from each experimental group with its respective control group. Statistical differences approaching $\mathrm{p}<0.05$ were considered statistically significant. 


\section{Results}

Nanoparticle characterization \& cisplatin

entrapment \& loading efficiency

The average nanoparticle sizes are listed in Table 1 and ranged from 141 to $187 \mathrm{~nm}$; the DLS data for each kind of nanoparticle is shown in Figure 2A-C. Surface charges of the nanoparticles are also listed in Table 1. The TEM images (Figure 2D-E) support the DLS data. The entrapment efficiency of cisplatin in the nanoparticles was around $70-75 \%$, and the loading efficiency was around $8 \% \mathrm{w} / \mathrm{w}$ in the nanoformulation (Figure 3 ).

Anticancer efficacy \& tumor uptake of cisplatin Urinary bladder cancer xenografts \& PLGA-

cisplatin or NDAT-cisplatin

Progressive increase in volume of control tumors (253JBV cells + void PLGA) over the 2 weeks of the protocol is shown in Figure 4A, in which all six treatments are compared. Tumor weights at animal sacrifice (Figure $4 B$ ) in this short-term study revealed that NDAT-cisplatin was significantly more effective than PLGA-cisplatin ( $50 \%$ reduction in weight, $\mathrm{p}<0.01)$. As expected, cisplatin alone had a modest effect on tumor weight. Use of NDAT as a delivery vehicle involves suboptimal anticancer concentrations of the drug $(0.3$ $\mathrm{mg} / \mathrm{kg}$ ), but there was nonetheless a significant antitumor effect seen with NDAT alone. Figure $4 \mathrm{C}$ shows the tumor content of cisplatin achieved with cisplatin alone, with PLGA-cisplatin, and with NDAT-cisplatin. Here, the level of cisplatin achieved in bladder tumors with cisplatin loaded into NDAT (NDAT-cisplatin) was fivefold that obtained with cisplatin alone, and 2.5-fold that achieved with PLGA-cisplatin. Both results were significant at $\mathrm{p}<0.001$. Also observed was back limb spasticity with unmodified cisplatin compared with NDAT-cisplatin treated animals at the end of treatment (Supplementary Figure 1).

Body weights of intact animals

There were no changes in body weights of the xenografted animals, controls or drug-exposed.

In vitro luciferase assay for NF- $\mathrm{KB}$ inhibition

Cisplatin at different concentrations ranging from 1-10 $\mu \mathrm{M}$ demonstrated a concentration-dependent increase in NF- $\kappa \mathrm{B}$ activity in HeLa cells, and DAT at $3 \mu \mathrm{M}$ inhibited cisplatin-induced NF- $\kappa \mathrm{B}$ activity (Figure 5A). The inhibition by DAT was shown to be a function of the cisplatin concentration used. Cisplatin at $10 \mu \mathrm{M}$ induced NF- $\kappa \mathrm{B}$ activity in HeLa cells, which was inhibited in the presence of the standard NF- $\mathrm{\kappa B}$ inhibitor, QNZ, at $1 \mu \mathrm{M}$ by $42.4 \%$, DAT at $1 \mu \mathrm{M}$ by $27.0 \%$ or NDAT at $1 \mu \mathrm{M}$ by $66.8 \%$ (Figure $5 \mathrm{~B}$ ).

\section{Discussion}

Existence of a receptor for thyroid hormone on the extracellular domain of integrin $\alpha v \beta 3$ [22] was disclosed more than a decade ago. This integrin is generously expressed in the plasma membrane of cancer cells and of dividing endothelial cells. Studies of the thyroid hormone receptor on $\alpha v \beta 3$ have enabled recognition of the existence of multiple thyroid hormone-regulated molecular control mechanisms for cancer cell proliferation, survival pathways and for angiogenesis $[23,24]$. Tetrac is a naturally occurring deaminated analog of L-thyroxine $\left(\mathrm{T}_{4}\right)$ that has been shown to block actions of thyroxine at the integrin, as well as actions of the principal intracellular agonist thyroid hormone, 3,3',5-triiodo-L-thyronine $\left(\mathrm{T}_{3}\right)$ [23]. In order to limit cellular uptake of tetrac and to focus its actions primarily on its receptor on integrin $\alpha v \beta 3$, we covalently bound tetrac via a diaminopropane linker to nanoparticulate PLGA. This tetrac formulation (NDAT, Nano-diaminotetrac, Nanotetrac) has been shown to be an effective antitumor drug in vitro and in xenografts [25-29]. The reformulation has greater anticancer potency than tetrac and has a panel of antitumor and antiangiogenic properties beyond those due to inhibition of the binding of $\mathrm{T}_{4}$ and $\mathrm{T}_{3}$ at the integrin [23,24]. We chose to use urinary bladder cell xenografts because a principal clinical indication for cisplatin is for this type of carcinoma - there are 16,000 deaths annually in the USA due to this cancer.

We observed a size difference between void and drug-loaded PLGA nanoparticles, and this has also been reported by others [30]. It has been discussed in the literature that it might be indirect proof that the drug, in our case cisplatin, has been incorporated in the nanoparticles.

Table 1. Size and surface charge of the nanoparticles.

\begin{tabular}{|llll|}
\hline Nanoparticle & Size $(\mathrm{nm})$ & PDI & $\zeta$ potential $(\mathrm{mV})$ \\
Void & 141 & 0.169 & -5.64 \\
\hline NDAT & 127 & 0.120 & -8.29 \\
\hline NDAT-cisplatin & 187 & 0.104 & -6.32 \\
\hline NDAT: Nano-diamino-tetrac; PDI: Polydispersity index. & & \\
\hline
\end{tabular}




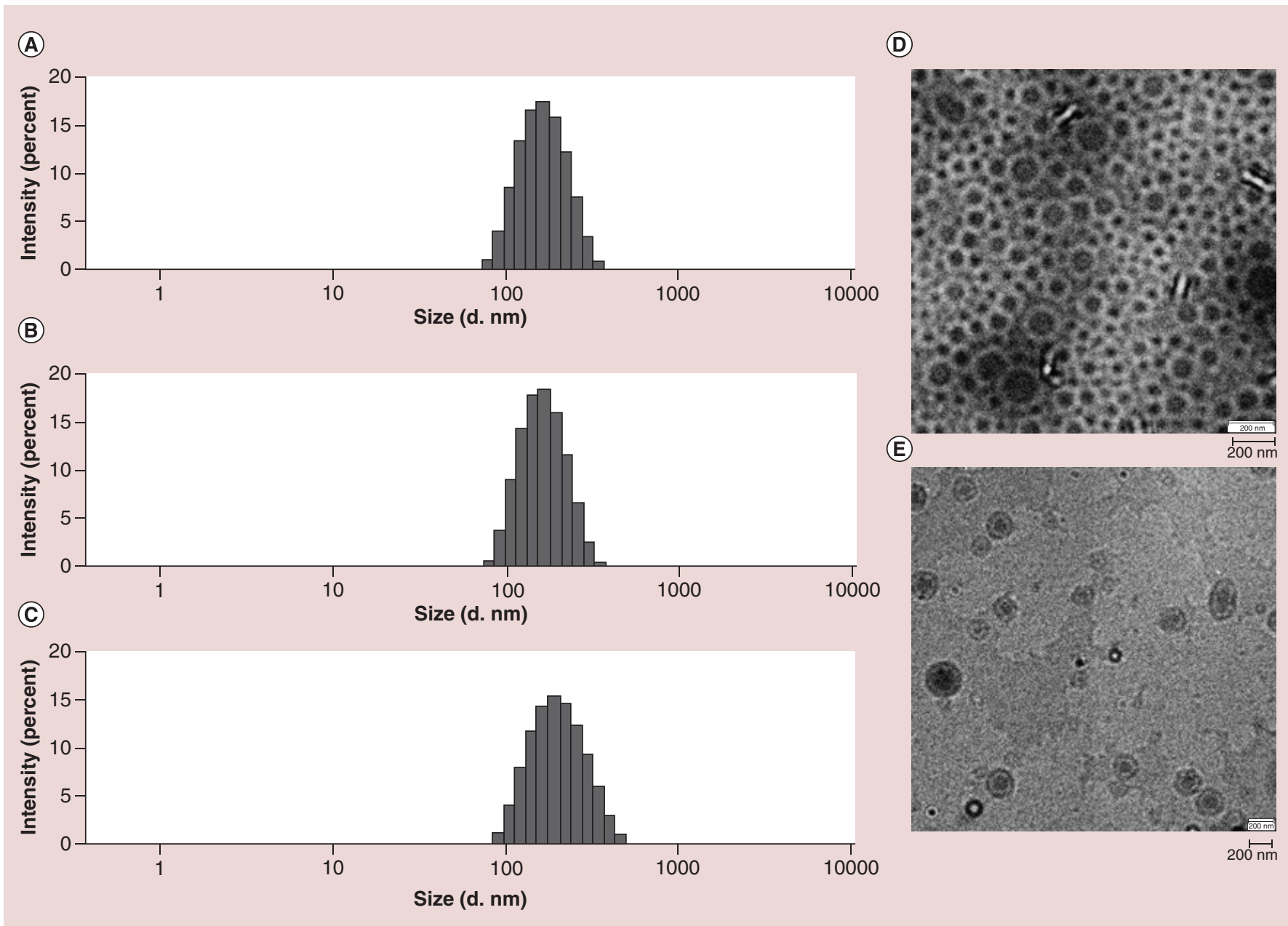

Figure 2. Size measurement of nanoparticles using dynamic light scattering. (A) Void poly(lactic-co-glycolic acid) nanoparticles. (B) Nano-diamino-tetrac (nanoparticulate tetraiodothyroacetic acid). (C) Nano-diamino-tetrac encapsulated with cisplatin. Transmission electron microscopy images showing the size of (D) Nano-diamino-tetrac and (E) Nano-diamino-tetrac encapsulated with cisplatin. The scale bar is $200 \mathrm{~nm}$.

The tissue distribution of the integrin supported development of the concept that NDAT - with its attendant large PLGA nanoparticle - may be a system for delivery of existing, widely used cancer chemotherapeutic agents to $\alpha v \beta 3$ and thus to tumors and their supporting vasculature [19]. The intent of the delivery system is to achieve increased intratumoral content of anticancer drug and reduce systemic toxicity. We present evidence in the current paper to validate this concept. Based on the description of NDAT and its PLGA nanoparticle - a payload delivery system described in 2010 patents [31] - Lee et al. [32] constructed a tetracliposome by which to deliver a lipid-soluble anticancer agent, edelfosine, to cancer xenografts. These authors reported increased antitumor activity of the combination but did not measure intratumoral chemotherapeutic concentration.

We show here that the loading with cisplatin of the PLGA nanoparticle covalently linked to tetrac resulted in a fivefold or greater increase in tumor content of the chemotherapeutic agent compared with conventional drug administration. We also found that encapsulating cisplatin in unmodified PLGA, in other words, PLGA that is not attached to tetrac and thus is not a tumortargeting system, did provide an increase in tumor uptake of drug. There was, as expected, improvement in tumor response to the chemotherapeutic drug payload delivered by NDAT to bladder carcinoma xenografts.

Administered conventionally, cisplatin has an appreciable risk of neurotoxicity. In the current studies, we observed hind limb spasticity with unmodified cisplatin administration for 2 weeks but no loss of function in animals receiving NDAT-cisplatin (Supplementary Figure 1). The multifold increase in tumor content of cisplatin is consistent with our contention of the cancer-targeting property of NDAT [23,24].

The dose of NDAT $(0.3 \mathrm{mg} / \mathrm{kg}$ tetrac equivalent daily) that was used in our studies as a delivery vehi- 
(A)

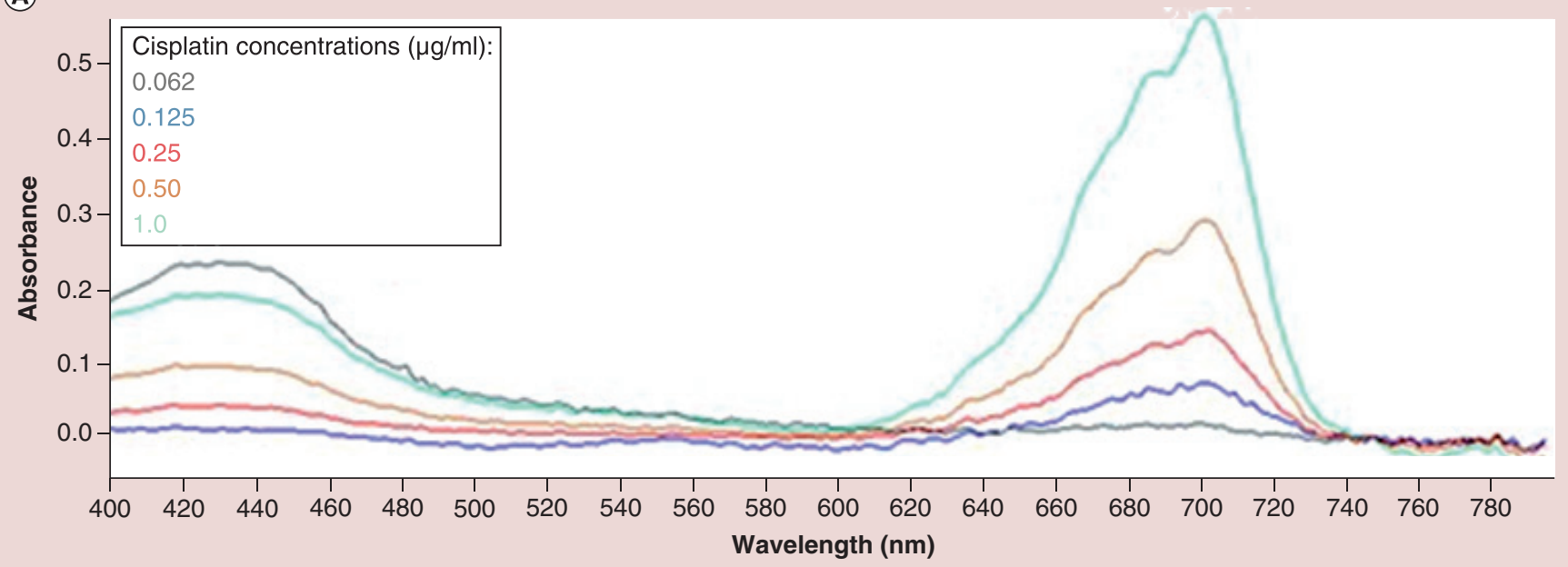

(B)

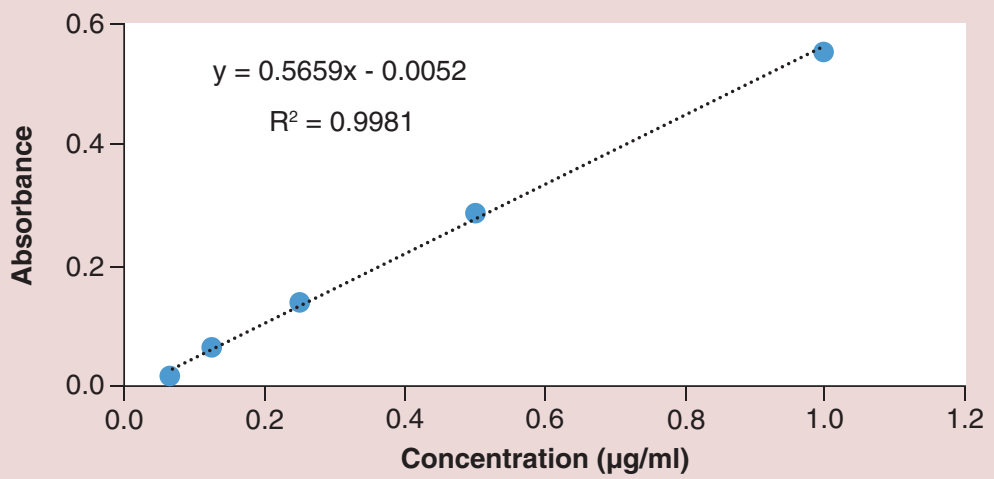

(C)

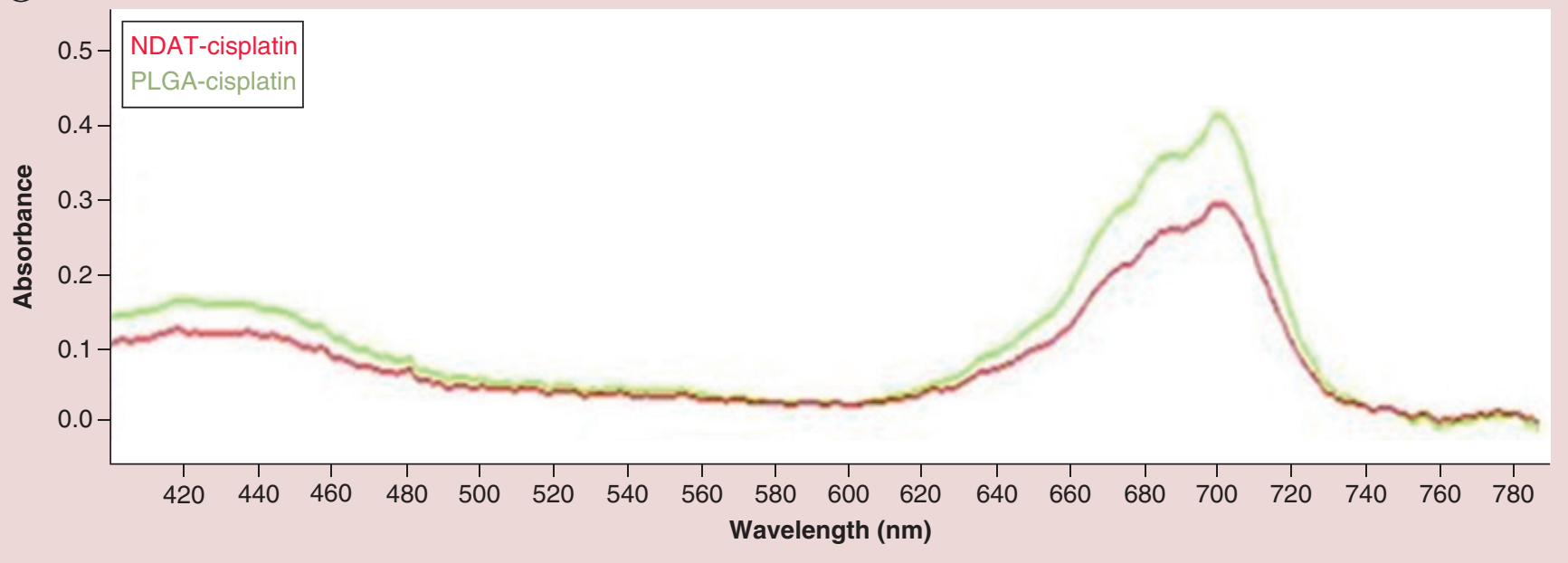

Figure 3. Cisplatin entrapment and loading efficiency for nanoparticles encapsulated with cisplatin. (A) UV-Vis spectra used to construct the standard curve (B), with concentrations of cisplatin from $0.062 \mu \mathrm{g} / \mathrm{ml}$ to $1.0 \mu \mathrm{g} / \mathrm{ml}$. (C) UV-Vis spectra for the nanoparticles (NDAT-cisplatin and PLGA-cisplatin).

NDAT: Nano-diamino-tetrac; PLGA: Poly(lactic-co-glycolic acid).

cle is suboptimal in terms of chemotherapeutic efficacy when compared with administration of NDAT, alone at $1.0 \mathrm{mg} / \mathrm{kg}$ tetrac equivalent, in management of tumor xenografts [33]. Thus, as we intended, the antitumor effectiveness measured here examines primarily the efficiency of NDAT in delivery of cisplatin, not additive or synergistic antitumor effects of NDAT with the other agents. However, such additive effects 
may exist [33]. Antitumor effectiveness of the drug formulation was verified in the current studies by tumor shrinkage in subcutaneous xenografts of urinary bladder cancer.

Cisplatin is known to induce oxidative stress and inflammatory response via NF- $\kappa \mathrm{B}$ pathways, which are implicated in cisplatin-associated adverse effects [34,35]. Thus, the absence of lower limb neuropathy in animals treated with NDAT-cisplatin may reflect the reduced exposure of nerves to cisplatin - which was delivered primarily to the tumors - and the capacity of NDAT, itself, to block any action of cisplatin on NF- $\kappa \mathrm{B}$ that

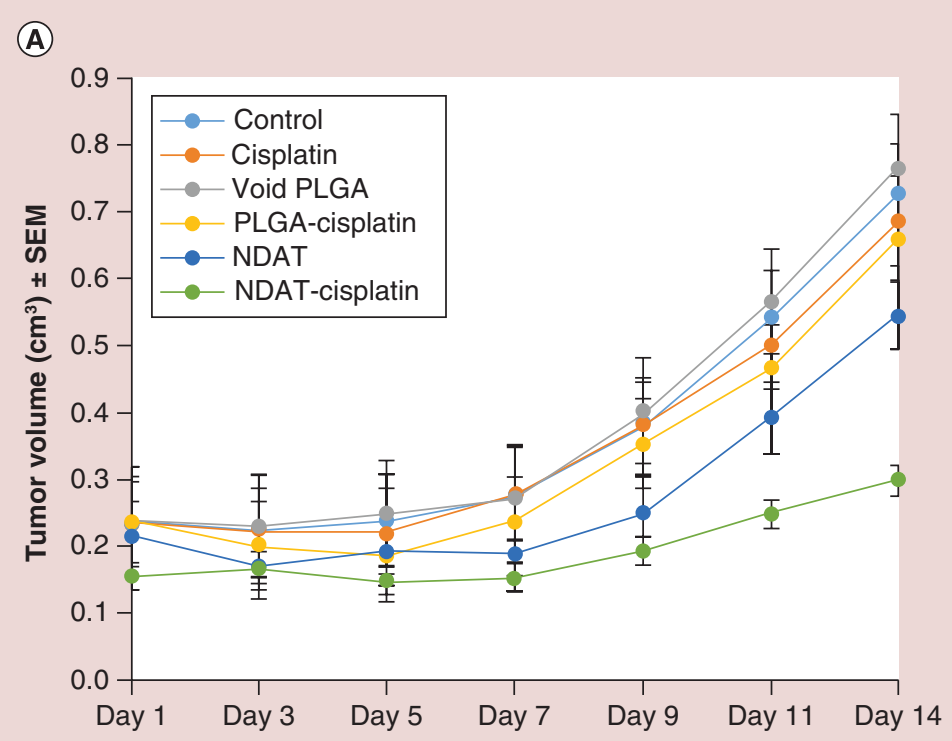

(B)

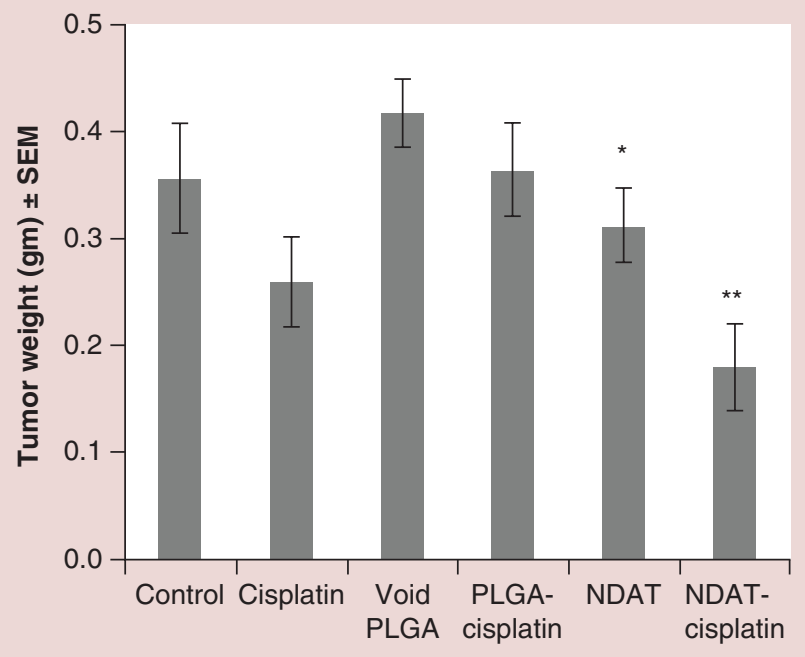

(C)

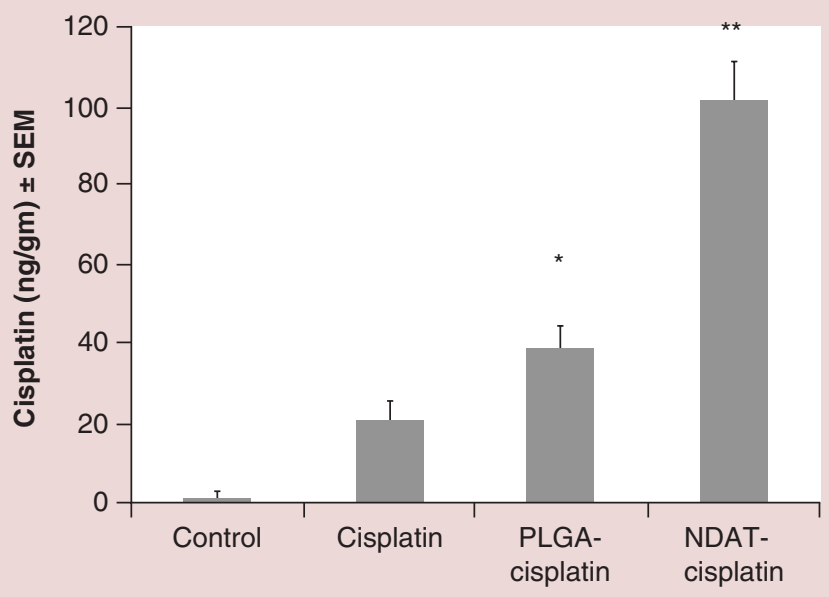

Figure 4. Effects on tumors of urinary bladder 253JBV cancer cell xenografts of daily subcutaneous administration of control (PBS), cisplatin, void poly(lactic-co-glycolic acid), poly(lactic-co-glycolic acid)-cisplatin (1 $\mathrm{mg} / \mathrm{kg} \mathrm{bw}$ cisplatin encapsulated in poly(lacticco-glycolic acid) nanoparticles, without tetrac), low dose nano-diamino-tetrac $(0.3 \mathrm{mg} / \mathrm{kg}$ bw tetrac equivalent, with empty payload compartment) and nano-diamino-tetrac-cisplatin $(0.3 \mathrm{mg} / \mathrm{kg}$ bw tetrac equivalent nano-diamino-tetrac with a payload of cisplatin at $1 \mathrm{mg} / \mathrm{kg}$ bw). Treatments were administered daily for 14 days, subcutaneously on the side of the animal away from the tumors, and tumor volume was measured twice a week with calipers. (A) Tumor volumes. Volumes were estimated from caliper measurements. (B) Tumor weights. Weights were measured of harvested grafts at animal sacrifice. NDAT-cisplatin treatment effect was significantly greater than effects of all other agents. ${ }^{*} p<0.05$ versus void PLGA, ${ }^{*} p<0.01$ versus void PLGA, PLGA-cisplatin or NDAT. (C) Cisplatin uptake by bladder tumors in response to administration of control (PBS), cisplatin, PLGA-cisplatin and NDAT-cisplatin measured with LC-MS/MS. NDAT-cisplatin resulted in tumor drug content fivefold that of cisplatin alone and 2.5 -fold that of PLGA-cisplatin. ${ }^{*} p<0.05$ versus cisplatin; **p 0.0001 versus cisplatin or PLGA-cisplatin.

NDAT: Nano-diamino-tetrac; PLGA: Poly(lactic-co-glycolic acid); SEM: Standard error of the mean. 


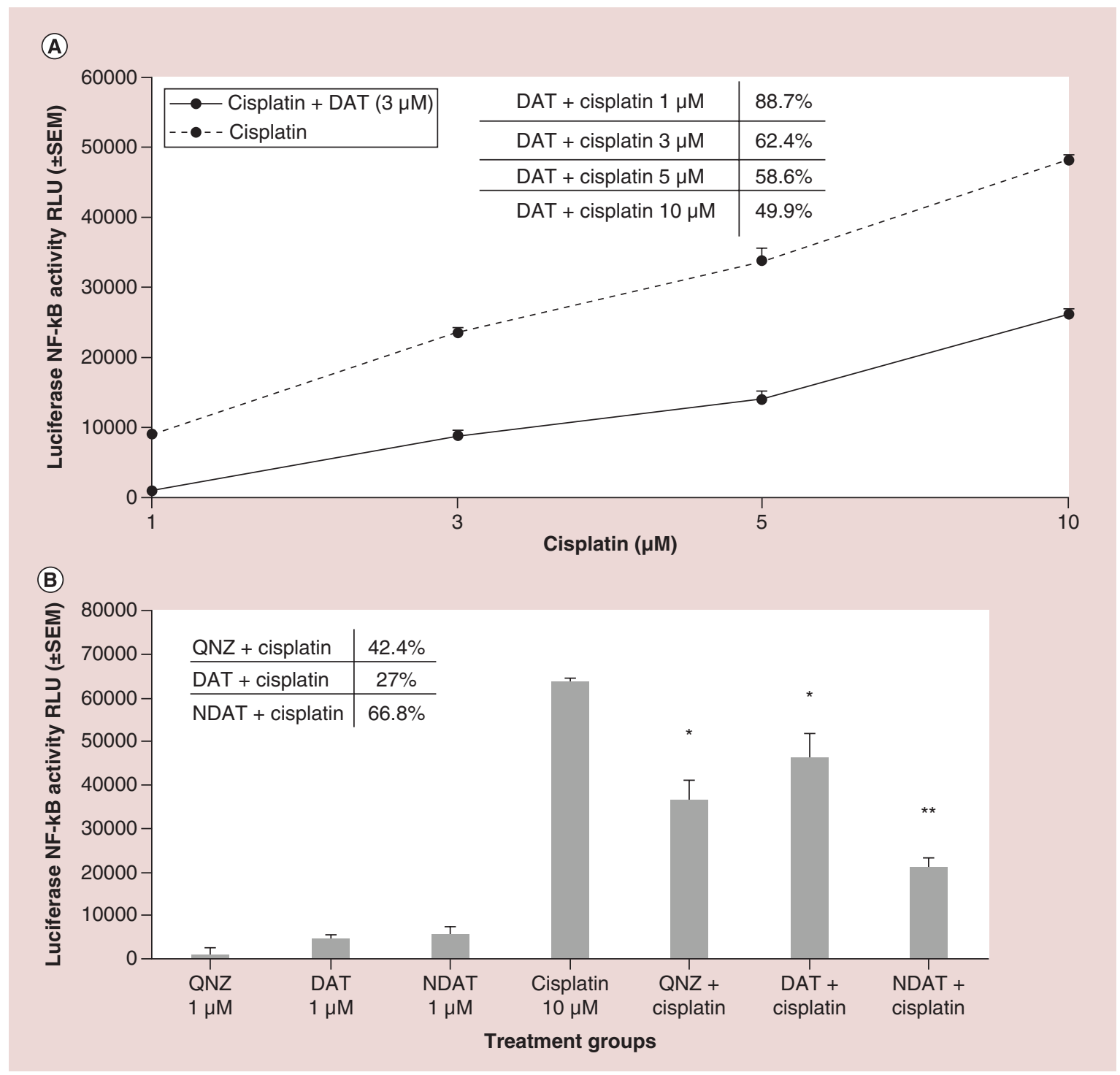

Figure 5. In vitro luciferase assay, showing cisplatin induces NF- $\kappa$ B and its inhibition by diamino-tetrac or nanodiamino-tetrac. Luciferase expression induced by cisplatin at different concentrations ranging from 1.0 to $10 \mu \mathrm{M}$ was quantified as the relative light units normalized to readings of control wells and expressed as relative NF- $\kappa B$ reporter activity. The mean \% inhibitory effects of the test compounds (QNZ, DAT or NDAT) were calculated.

(A) DAT at $3.0 \mu \mathrm{M}$ inhibited cisplatin-induced NF- $\kappa$ B activity in a dose-dependent manner that is dependent on the cisplatin concentration used. (B) QNZ, DAT and NDAT at $1.0 \mu \mathrm{M}$ inhibited cisplatin $(10 \mu \mathrm{M})$-induced NF- $\kappa \mathrm{B}$ activity in HeLa cells. Data represent mean \pm standard error of the mean, $n=3,{ }^{*} p<0.05 ;{ }^{* *} p<0.01$ compared with $10 \mu \mathrm{M}$ cisplatin.

DAT: Diamino-tetrac; NDAT: Nano-diamino-tetrac; QNZ: Quinazolinediamine; RLU: Relative light unit;

SEM: Standard error of the mean.

might have occurred via the systemic circulation. We demonstrated this action of NDAT in the current paper. Our studies demonstrated that DAT or NDAT suppressed NF- $\kappa \mathrm{B}$ induced by cisplatin in contrast to the NF- $\kappa B$ inhibitor, QNZ. This NDAT effect in limiting cisplatin-induced NF- $\kappa B$ activity is in addition to its tumor-targeting capabilities in delivering a greater load of cisplatin into bladder tumor. These data suggest a greater impact of NDAT on the adverse effects mediated by cisplatin via different pathways.

\section{Conclusion}

In this preclinical study, we report that cancer xenograft uptake of cisplatin is up to fivefold greater with nanoparticulate NDAT delivery than with conventional drug administration. Correspondingly greater antitumor effect of the chemotherapeutic agent was achieved with NDAT delivery. Neurotoxicity was avoided with NDAT-coupled administration of cisplatin, indicating reduction in risk of systemic toxicity with this method of drug delivery. 
Supplementary data

To view the supplementary data that accompany this paper please visit the journal website at: www.futuremedicine.com/ doi/full/10.2217/nnm-2016-0315

Financial \& competing interests disclosure

This work was supported in part by a grant from NanoPharmaceuticals LLC (NY, USA). PJ Davis and SA Mousa are stockholders in NanoPharmaceuticals LLC that is commercially developing Nano-diamino-tetrac (NDAT) and PJ Davis is an officer of the company. KA Keating is paid as a consultant by NanoPharmaceuticals LLC. The authors have no other relevant affiliations or financial involvement with any organization or entity with a financial interest in or financial conflict with the subject matter or materials discussed in the manuscript apart from those disclosed.
No writing assistance was utilized in the production of this manuscript.

\section{Ethical conduct of research}

The authors state that they have obtained appropriate institutional review board approval or have followed the principles outlined in the Declaration of Helsinki for all human or animal experimental investigations. In addition, for investigations involving human subjects, informed consent has been obtained from the participants involved.

\section{Open access}

This work is licensed under the Attribution-NonCommercialNoDerivatives 4.0 Unported License. To view a copy of this license, visit http://creativecommons.org/licenses/by-nc$\mathrm{nd} / 4.0 /$

\section{Executive summary}

\section{Background}

- Tumor-targeted nano-carriers can be designed to deliver chemotherapy payloads to tumor sites with improved efficacy and safety of cancer therapy.

- Nano-diamino-tetrac (NDAT; Nanotetrac, nanoparticulate tetraiodothyroacetic acid) is a nanoparticulate formulation in which a cancer cell-targeting moiety, tetrac, is covalently linked to a nanoparticle.

- NDAT can be loaded with cisplatin that is released in the tumor microenvironment when the tetrac binds specifically to integrin $\alpha v \beta 3$ expressed by tumor cells. Nonmalignant cells bear substantially less $\alpha v \beta 3$ than do tumor cells.

\section{Materials \& methods}

- We examined the delivery efficacy of NDAT with a payload of cisplatin for targeted delivery to 253JBV urinary bladder cancer xenografts in nude mice.

\section{Results}

- In this preclinical study, we show that cancer tumor uptake of cisplatin is up to fivefold greater with NDAT delivery than with conventional drug administration; there is correspondingly greater antitumor effect of the chemotherapeutic agent.

- Neurotoxicity was also avoided with NDAT drug delivery, thus achieving the goals of enhanced drug uptake by tumor and reduced risk of toxicity.

- We found that encapsulating cisplatin in unmodified poly(lactic-co-glycolic acid) nanoparticle, in other words, poly (lactic-co-glycolic acid) that is not attached to tetrac and thus is not a tumor-targeting system, provided modest increases in tumor uptake of drug.

\section{Conclusion}

- We report a nanoparticulate model system for cisplatin chemotherapy delivery that specifically targets urinary bladder tumors and their attendant vascularization, both of which express plasma membrane integrin $\alpha v \beta 3$. The integrin bears a receptor for tetrac, enabling tumor-targeted delivery of drug payload.

- Local release at cancer xenograft site of cisplatin resulted in significant improvement in tumor uptake of drug compared with standard systemic administration of this agent.

\section{References}

Papers of special note have been highlighted as: • of interest

1 Dilruba S, Kalayda GV. Platinum-based drugs: past, present and future. Cancer Chemother. Pharmacol. 77(6), 1103-1124 (2016).

2 Matsusaka S, Lenz HJ. Pharmacogenomics of fluorouracilbased chemotherapy toxicity. Expert Opin. Drug Metab. Toxicol. 11(5), 811-821 (2015).

3 Chan ES, Cronstein BN. Mechanisms of action of methotrexate. Bull. Hosp. Jt. Dis. 71(Suppl. 1), S5-S8 (2013).
4 Rivankar S. An overview of doxorubicin formulations in cancer therapy. J. Cancer Res. Ther. 10 (4), 853-858 (2014).

5 Barbuti AM, Chen ZS. Paclitaxel through the ages of anticancer therapy: exploring its role in chemoresistance and radiation therapy. Cancers 7(4), 2360-2371 (2015).

6 Ulbrich K, Hola K, Subr V, Bakandritsos A, Tucek J, Zboril R. Targeted drug delivery with polymers and magnetic nanoparticles: covalent and noncovalent approaches, release control, and clinical studies. Chem. Rev. 116(9), 5338-5431 (2016). 
7 Arosio D, Casagrande C. Advancement in integrin facilitated drug delivery. Adv. Drug Deliv. Rev. 97, 111-143 (2016).

8 Linton SS, Sherwood SG, Drews KC, Kester M. Targeting cancer cells in the tumor microenvironment: opportunities and challenges in combinatorial nanomedicine. Wiley Interdiscip. Rev. Nanomed. Nanobiotechnol. 8(2), 208-222 (2016).

9 Oberoi RK, Parrish KE, Sio TT, Mittapalli RK, Elmquist WF, Sarkaria JN. Strategies to improve delivery of anticancer drugs across the blood-brain barrier to treat glioblastoma. Neuro. Oncol. 18(1), 27-36 (2016).

10 Soudy R, Byeon N, Raghuwanshi Y, Ahmed S, Lavasanifar A, Kaur K. Engineered peptides for applications in cancer targeted drug delivery and tumor detection. Mini Rev. Med. Chem.16, doi:10.2174/1389557516666160219121836 (2016) (Epub ahead of print).

11 Yang Y, Yu C. Advances in silica based nanoparticles for targeted cancer therapy. Nanomedicine 12(2), 317-332 (2016).

12 Johnstone TC, Suntharalingam K, Lippard SJ. The next generation of platinum drugs: targeted pt(II), agents, nanoparticle delivery, and pt(IV), prodrugs. Chem. Rev. 116(5), 3436-3486 (2016).

13 Wang X, Guo Z. Targeting and delivery of platinumbased anticancer drugs. Chem. Soc. Rev. 42(1), 202-224 (2013).

14 Davis PJ, Goglia F, Leonard JL. Nongenomic actions of thyroid hormone. Nat. Rev. Endocrinol. 12(2), 111-121 (2016).

15 Lü JM, Wang X, Marin-Muller C et al. Current advances in research and clinical applications of PLGA-based nanotechnology. Expert Rev. Mol. Diagn. 9(4), 325-341 (2009).

16 Desgrosellier JS, Cheresh DA. Integrins in cancer: biological implications and therapeutic opportunities. Nat. Rev. Cancer 10(1), 9-22 (2010).

17 Somanath PR, Ciocea A, Byzova TV. Integrin and growth factor receptor alliance in angiogenesis. Cell Biochem. Biophys. 53(2), 53-64 (2009).

18 Thangirala S, Bharali DJ, Yalcin M et al. Targeted delivery of paclitaxel and doxorubicin to cancer xenografts via the nanoparticle of nano-diamino-tetrac. Int. J. Nanomed. (2016) (In Press).

19 Bharali DJ, Yalcin M, Davis PJ, Mousa SA. Tetraiodothyroacetic acid-conjugated PLGA nanoparticles: a nanomedicine approach to treat drug-resistant breast cancer. Nanomedicine (Lond.) 8(12), 1943-1954 (2013).

20 Basotra M, Singh SK, Gulati M. Development and validation of a simple and sensitive spectrometric method for estimation of cisplatin hydrochloride in tablet dosage forms: application to dissolution studies. ISRN Anal. Chem. 2013, 936254 (2013).

21 Golla ED, Ayres GH. Spectrophotometric determination of platinum with o-phenylenediamine. Talanta 20 (2), 199-210 (1973).
22 Bergh JJ, Lin HY, Lansing L et al. Integrin $\alpha v \beta 3$ contains a cell surface receptor site for thyroid hormone that is linked to activation of mitogen-activated protein kinase and induction of angiogenesis. Endocrinology 146(7), 2864-2871 (2005).

23 Davis PJ, Davis FB, Mousa SA, Luidens MK, Lin HY. Membrane receptor for thyroid hormone: physiologic and pharmacologic implications. Annu. Rev. Pharmacol. Toxicol. 51, 99-115 (2011).

24 Davis PJ, Glinsky GV, Lin HY et al. Cancer cell gene expression modulated from plasma membrane integrin $\alpha v \beta 3$ by thyroid hormone and nanoparticulate tetrac. Front. Endocrinol. (Lausanne) 5, 240 (2014).

25 Yalcin M, Lin HY, Sudha T et al. Response of human pancreatic cancer cell xenografts to tetraiodothyroacetic acid nanoparticles. Horm. Cancer 4(3), 176-185 (2013).

26 Yalcin M, Bharali DJ, Lansing L et al. Tetraidothyroacetic acid (tetrac), and tetrac nanoparticles inhibit growth of human renal cell carcinoma xenografts. Anticancer Res. 29(10), 3825-3831 (2009).

27 Mousa SA, Yalcin M, Bharali DJ et al. Tetraiodothyroacetic acid and its nanoformulation inhibit thyroid hormone stimulation of non-small-cell lung cancer cells in vitro and its growth in xenografts. Lung Cancer 76(1), 39-45 (2012).

28 Glinskii AB, Glinsky GV, Lin HY et al. Modification of survival pathway gene expression in human breast cancer cells by tetraiodothyroacetic acid (tetrac). Cell Cycle 8(21), 3562-3570 (2009).

29 Lin HY, Sun M, Tang HY et al. L-Thyroxine vs. 3,5,3 -triiodo-L-thyronine and cell proliferation: activation of mitogen-activated protein kinase and phosphatidylinositol 3-kinase. Am. J. Physiol. Cell Ph. 296(5), C980-C991 (2009).

30 Saha C, Kaushik A, Das A, Pal S, Majumder D. Anthracycline drugs on modified surface of quercetin-loaded polymer nanoparticles: a dual drug delivery model for cancer treatment. PLoS ONE 11(5), e0155710 (2016).

31 Composition of matter patent application with cancer chemotherapy encapsulated was filed with the U.S. Patent and Trademark Office on 06/15/10 (Nanoparticle and Polymer Formulations for Thyroid Hormone Analogs, Antagonists and Formulations and Uses Thereof; application \#12/816287, patent \#9,220,788 issued). Method of treatment patent application using Nanotetrac with the chemotherapeutic agent encapsulated was filed with the U.S. Patent and Trademark Office on 11/16/10 (Nanoparticle and Polymer Formulations for Thyroid Hormone Analogs, Antagonists and Formulations and Uses thereof; application \#12/947,389, patent \#9,289,395 issued).

32 Lee S, Kim J, Shim G et al. Tetraiodothyroacetic acid-tagged liposomes for enhanced delivery of anticancer drug to tumor tissue via integrin receptor. J. Control. Release 164(2), 213-220 (2012).

33 Lin HY, Landersdorfer CB, London D et al. Pharmacodynamic modeling of anti-cancer activity of tetraiodothyroacetic acid in a perfused cell culture system. PLoS Comput. Biol. 7(2), e1001073 (2011). 
34 Chtourou Y, Aouey B, Kebieche M, Fetoui H. Protective role of naringin against cisplatin induced oxidative stress, inflammatory response and apoptosis in rat striatum via suppressing ROS-mediated NF-kappaB and P53 signaling pathways. Chem. Biol. Interact. 239, 76-86 (2015).
35 Sharawy N, Rashed L, Youakim MF. Evaluation of multineuroprotective effects of erythropoietin using cisplatin induced peripheral neurotoxicity model. Exp. Toxicol. Pathol. 67(4), 315-322 (2015). 